\title{
Critical considerations about the onset and epidemiology of whiplash associated disorders presented by the bone and joint decade 2000-2010 task force on neck pain
}

\author{
Eythor Kristjansson* \\ Communication and Research Unit for Musculoskeletal Disorders, Division for Neuroscience and Musculoskeletal Medicine, Oslo University Hospital, Norway
}

\begin{abstract}
Background: The Neck Pain Task Force (NPTF) invites a constructive dialogue on how to best decrease the personal and societal burden of neck pain and its associated disorders. A critical review of the NPTF own literature synthesis on the onset and epidemiology of whiplash associated disorders (WAD) is well suited to ascertain whether the NPTP has achieved its stated goal concerning linking onset, course and care of a condition which contrasting views are no less conflicting now than almost seventy years ago.

Discussion: The NPTP review of possible mechanisms of injury to the neck is not trustworthy. Firstly, the NPTF choose to skip all research, expect 2 experimental studies. Secondly, the NPTF then states that the current evidence does not allow us to draw any conclusions about a specific injury mechanism, if one exists. A literature review was conducted by the author on this issue, within the frame of NPTF literature review period, 1980-2006, which showed remarkable consistency both across different methodologies and different research teams which possess high degrees of external validity to the aforementioned biomechanical research on low velocity whiplash biomechanics.

Scrutinizing the NPTF work on incidence, prevalence, course and prognosis of WAD, it was striking how often the members of the NPTF scientific jury emphasize that neck pain and its associated disorders is also prevalent in the general population. A closer look at the NPTF own literature synthesis revealed that prior neck injuries are a confounding factor that must be controlled for in future studies about the prevalence of neck pain in the general population.
\end{abstract}

Summary: The onset and epidemiology of WAD are controversial as demonstrated by NPTF and the critical considerations presented herein. It is of major concern to rule in the late whiplash syndrome and identifying predictors and potentially mitigating chronic neck pain, and especially so in more severe cases.

\section{Background}

The results of the work by The Bone and Joint Decade 2000-2010 Task Force on Neck Pain and its Associated Disorders was published as a supplement in the February 15, 2008 issue of the Spine [1]. This work was generated through ongoing discussions by a multidisciplinary Scientific Secretariat, spanning 6 years, reviewing the international literature on this topic [2]. The NPTF has delivered a major undertaking towards bringing neck pain of musculoskeletal origin, which maintains a low status within the hierarchy of contemporary medicine [3], into the limelight. The NPTF recommendations about research priorities and methodological implications are invaluable guidelines for researchers [4]. Broadly, it can be asserted that the NPTF research priorities as well as recommendations suggest what should be done (emphasis added) and the NPTF review articles highlight what has been done (emphasis added). It is therefore of concern how the mismatch between the two highlighted matters is interpreted. Whiplash associated disorders (WAD) is well suited to ascertain whether the NPTP has achieved its stated goal concerning linking onset, course and care of a condition which contrasting views are no less conflicting now than nearly seventy years ago [5].

The NPTF states "The Neck Pain Task Force hopes that our new conceptual model for the onset, course, and care of neck pain will signal a shift in our thinking about this widespread problem, and that it will open a constructive dialogue on how to best decrease the personal and societal burden of neck pain and its associated disorders" [2].
The objective of the present debate is to open such a dialogue about the onset and epidemiology of WAD.

\section{Discussion}

\section{The Onset of WAD}

The NPTP review of possible mechanisms of injury to the neck is not trustworthy. Firstly, the NPTF choose to skip all research, expect 2 experimental studies involving volunteers' exposure to low-speed collision (speed changes $4-8 \mathrm{~km} / \mathrm{h}$ ) and a sham collision, exploring possible mechanisms of injury to the neck [6]. Secondly, the NPTF then states "However, the current evidence does not allow us to draw any conclusions about a specific injury mechanism, if one exists" [6]. Therefore, the NPTF prior citation in the same article to Farmer et al. [7] at Insurance Institute for Highway Safety seems to be out of context, but it reads as follows "...found that active devices such as active head

${ }^{\star}$ Correspondence to: Eythor Kristjansson, PT. PhD., Communication and Research Unit for Musculoskeletal Disorders, Division for Neuroscience and Musculoskeletal Medicine (FORMI), Vækeröveien 23, N-0282 Oslo University Hospital, Ullevål, 0407, Oslo, Norway, Tel: +47 92353 722; E-mail: eythork@ simnet.is

Key words: whiplash, injury mechanisms, onset, epidemiology

Received: May 25, 2020; Accepted: June 16, 2020; Published: June 20, 2020 
Kristjansson E (2020) Critical considerations about the onset and epidemiology of whiplash associated disorders presented by the bone and joint decade 2000-2010 task force on neck pain

rests and seat backs were associated with an overall $43 \%$ reduction in WAD claims in favour of the devices" [6].

What is the function of the afore mentioned devices? The device, which is activated in rear - end collisions, is to have seat and head restraint which reduces the opposite movements of the head and trunk, i.e., keep the body and the head moving together to reduce the strain on the neck and to reduce the risk of neck injury [8]. Therefore, it is difficult to understand why NPTF scientific jury omitted the literature about low speed whiplash biomechanisms. In fact, biomechanical research into low velocity whiplash biomechanics, conducted within the frame of NPTF literature review period, 1980-2006, has shown remarkable consistency both across different methodologies and different research teams which possess high degrees of external validity to the aforementioned biomechanical research. A research conducted in 2010 into low velocity whiplash biomechanics came to the following conclusion "The present results underscore the importance of neck injury prevention systems in minimizing spinal rotations during whiplash to reduce the resulting residual instability, pain, and chronic symptoms" [9].

\section{The Epidemiology of WAD}

One of the most important conclusions made by the NPTF is that the annual incidence of WAD in North America and Western Europe is estimated to be at least 300 per 100,000 inhabitants [6]. As the incidence of WAD is among the most controversial epidemiological issues in medicine today $[10,11]$ a more thorough analysis of the underlying causes for the diverging incidence rates between countries and even within the same country as reported by the NPTF [12] would have been much appreciated.

However, the most likely explanation for the diverging incidence rates across the Nordic countries [13] and other countries [10], which share a common cultural background and life-style standard, is the different registration strategies and/or different injury registration sources. Moreover, the editorial - "Stopping late whiplash: Which way to Utopia?" [14] may give interested readers some insight into other reasons for the diverging incidence rates. Unpublished observations made by the author indicate that the diagnosis of WAD (ICD-9 diagnostic code 847.0 -cervical sprains and strains, including whiplash injuries) may be hidden by other diagnostic codes in some countries like Norway.

Scrutinizing the NPTF work on incidence, prevalence, course and prognosis of WAD, it was striking how often the members of the NPTF scientific jury emphasize that neck pain and its associated disorders is also prevalent in the general population [1]. The NPTF states "The best evidence suggests that between $20 \%$ and $40 \%$ of the general population reports having experienced neck pain during the previous month" [12]. The NPTF estimates the 12-month prevalence of neck pain in the general population to be $30-50 \%$ [15]. Accordingly, referring to WAD, the NPTF states "The clinical diagnosis is also confused by the high prevalence of neck pain and other WAD-like symptoms in the general population and in the working population" [13]. When reporting about the course and prognosis of WAD, the NPTF states: "The preponderance of evidence indicates that, in adults, recovery of WAD is prolonged, with approximately half of those affected reporting neck pain symptoms 1 year after the injury. However, this should be interpreted in light of the background prevalence of neck pain" [12]. These disclaimers, made by the NPTF, gave the author the impression that symptoms in WAD have similar characteristics to symptoms vocalized by people in the general population.
The NPTF also implies that patients with WAD may simply be attributing some prior symptoms, prone in the general population, to an accident or a mishap [12]. It seems appropriate, therefore, to take a closer look at the evidences put forward by the NPTF, which underpinned their incidence and prevalence rates of neck pain in the general population versus patients with WAD.

The age distribution in adults exposed to a whiplash mechanism to the neck has shown a remarkable consistency across countries with preponderance of the younger age groups between 16-24 years of age [16-19]. This is in contrast to the incidence rates of neck pain in the general population, reported by the NPTF, which peak incidence coincided with middle-age groups peaking at ages 40-49 and ages 3544, respectively [13]. This is in accordance with the fact, emphasised by the NPTF, that younger (WAD) age groups are at greater risk (emphasis added) to seek compensation for their pain and suffering as well as filing disability claims than older (WAD) age groups [6].

Quoting the references in the NPTF own literature synthesis reveals that their review has some essential shortcomings. Regarding incidence, the study by Croft et al., [20] who carried out a one-year prospective study on 7.669 individuals with no neck pain at baseline, came to the following conclusion "We have carried out a prospective study in a general population sample and demonstrated that established risk factors for chronic pain predict future episodes of neck pain, and shown that in addition a history of neck injury is an independent and distinct risk factor". Croft et al., further stated "This finding may have major public health and medicolegal implications" [20]. Unfortunately, the NPTF dismiss the word injury (emphasis added) when referring to this work, only stating "a history of neck pain, poor self-assessed health..." as independent risk factors for neck pain [13].

According to the NPTF, most estimates of 12 -month prevalence of neck pain in the general population were between $30-50 \%$ [13] However, when ascertaining the literature cited by the NPTF reporting the highest prevalence rates, over lifetime, at twelve-month and at onemonth, it became apparent that few studies claim that prior neck pain is a significant risk factor for subsequent neck pain $[21,22]$, while most studies in the NPTP literature synthesis did not mention at all whether people with prior neck injury (emphasis added) were included [23-31]. Prior neck injuries in the general population seems therefore to be a confounding factor that must be controlled for in future studies about incidence and prevalence rates of neck pain in the general populations. The afore mentioned disclaimers, made by the NPTF, regarding the incidence and prevalence rates in WAD, are therefore based on weak evidences. Few studies have been conducted comparing the prevalence of neck pain and disability in WAD with those in the general population [32-34]. In conclusion, a past history of neck injury appears to have a substantial impact on future persistent neck pain and disability [34].

\section{Ruling in the late whiplash syndrome}

The NPTF states "In North-America, about 5\% of the general population is disabled because of neck pain" [1]. Freeman et al., cautiously estimated that $6.2 \%$ of the US population, or circa 15.5 million individuals, have late whiplash syndrome [35]. Based on prior methodological objections made by the author in this paper, one may wonder: is this the same population? Whilst the NPTF looks upon $\mathrm{WAD}$ and other neck pain patients as the same population, explicitly stated by the NPTF "WAD and other neck pain do not differ once serious neck conditions have been ruled out" [36], there is no reason to assume that the NPTF overriding goal "to improve the health-related quality of life for people with musculoskeletal disorders throughout the world" [1], will be achieved. 
Kristjansson E (2020) Critical considerations about the onset and epidemiology of whiplash associated disorders presented by the bone and joint decade $2000-2010$ task force on neck pain

Although about $50 \%$ of patients with WAD have favourable prognosis (benign WAD) [12], and only need advice, assurance and informed instructions it is the other half that needs therapeutic attention. Much more efforts must be put in mitigating the transition from the acute phase to the chronic phase. It is therefore important to consider modifiable prognostic factors that may be identified in the early acute stage of the condition such that interventions may be more specifically directed towards those circa $10-20 \%$ who are at the greatest risk of becoming most disabled and costly for societies $[37,38]$. The bottom line is that it will be more favourable for patients and societies to try to understand the aetiology and burden of chronic WAD, rather than belittling WAD.

\section{Summary}

The onset and epidemiology of WAD are controversial as demonstrated by the NPTF literature review on these topics and the critical considerations presented herein. A comprehensive literature review on low velocity whiplash biomechanics, omitted by the NPTF, shows that whiplash consists of complicated injury mechanisms. It can be substantiated that the incidence and prevalence rates of WAD cannot be compared with the incidence and prevalence rates of neck pain in the general population as presented by the NPTF. Prior neck injuries in the general population are a confounding factor that must be controlled for in future epidemiologic studies about neck pain in the general and working populations. It is of major concern to rule in the late whiplash syndrome and identifying predictors of and potentially mitigating chronic neck pain, and especially so in more severe cases.

\section{Conflict of Interest}

There are no competing interests to declare.

\section{Acknowledgements}

This work was conducted as deputyship researcher at Communication and Research Unit for Musculoskeletal Disorders, Division for Neuroscience and Musculoskeletal Medicine (FORMI), Oslo University Hospital, Ullevål, 0407, Oslo, Norway.

\section{References}

1. Guzman J, Hurwitz E, Carroll L, Haldeman S, Côté P, et al. (2008) Results of the Bone and Joint Decade 2000-2010 Task Force on Neck Pain and its Associated Disorders. Spine 33: S1-220.

2. Guzman J, Hurwitz EL, Carroll LJ, Haldeman S, Côté P, et al (2008) A conceptual model for the course and care of neck pain. Results of the Bone and Joint Decade 2000-2010 Task Force on Neck Pain and its Associated Disorders. Spine 33: S14-23. [Crossref]

3. Freedman K, Bernstein J (1998) The adequacy of medical school education in musculoskeletal medicine. J Bone Joint Surg 80: 1421-1427. [Crossref]

4. Carroll LJ, Hurwitz EL, Côté P, Hogg-Johnson S, Carragee E, et al. (2008) Research priorities and methodological implications. Results of the Bone and Joint decade 2000-2010 Task Force on Neck Pain and Its Associated Disorders. Spine 33: S214 220. [Crossref]

5. Gay JR, Abbott KH (1953) Common whiplash injuries of the neck. J Am Med Assoc 152: 1698-1704. [Crossref]

6. Holm L, Carroll L, Cassidy D, Hogg-Johnson S, Côté P, et al. (2008) The Burden and determinants of neck pain in whiplash-associated disorders after traffic collisions. Results of the Bone and Joint decade 2000-2010 Task Force on Neck Pain and Its Associated Disorders. Spine 33: S52-59. [Crossref]

7. Farmer CM, Wells JK, Lund AK (2002) Effects of Head Restraint and Seat Redesign on Neck Injury Risk in Rear-End Crashes. Arlington, VA: Insurance Institute for Highway Safety.

8. http://www.youtube.com/watch?v=rXH3auUmOkM
9. Ivancic PC, Sha D, Lawrence BD, Mo F (2010) Effect of active head restraint on residual neck instability due to rear impact. Spine 35: 2071-2078. [Crossref]

10. Ferrari R, Russell A (1999) Epidemiology of whiplash: an international dilemma. Ann Rheum Dis 58: 1-5. [Crossref]

11. Bogduk N (2000) Epidemiology of whiplash. Ann Rheum Dis 59: 394-396. [Crossref]

12. Carroll L, Holm L, Hogg-Johnson S, Côté P, Cassidy D, et al. (2008) Course and prognostic factors for neck pain in whiplash - associated disorders (WAD). Results of the Bone and Joint Decade 2000-2010 Task Force on Neck Pain and Its Associated Disorders. Spine 33: S83-82. [Crossref]

13. Kristjansson E (2004) Clinical characteristics of whiplash associated disorders (WAD) grades I-II: Investigation into the stability system of the cervical spine. PhD thesi ISBN: 99979-9513-3-8. University of Iceland, Faculty of Medicine, Reykjavik, Iceland.

14. Harth M (2008) Stopping late whiplash: Which way to Utopia? J Rheumatol 35: 23032305.

15. Hogg-Johnson S, van der Velde G, Carroll L, Holm L, Cassidy D, et al. (2008) The Burden and determinants of neck pain in the general population. Results of the Bone and Joint Decade 200-2010 Task Force on Neck Pain and Its Associated Disorders. Spine 33: S39-51. [Crossref]

16. Bring G (1996) Whiplash-associated injuries and disorders - Biomedical aspects of a multifaceted problem. PhD thesis. ISBN: 91-7045-569-4 Umeå University, Sweden, Department of Family Medicine.

17. Spitzer WO, Skovron ML, Salmi LR, Cassidy JD, Duranceau J, et al. (1995) Scientific Monograph of the Quebec Task Force on Whiplash-Associated Disorders: Redefining "Whiplash" and its Management. Spine 20: 1S -73S. [Crossref]

18. Quinlan KP, Annest JL, Myers B, Ryan G, Hill H (2004) Neck strains and sprains among motor vehicle occupants - United States. Accid Anal Prev 36: 21-27. [Crossref]

19. Ferrando J, Plaséncia A, MacKenzie E, Orós M, Arribas P, et al. (1998) Disability Resulting from traffic injuries in Barcelona, Spain: 1-year incidence by age, gender and type of user. Accid Anal Prev 30: 723-730. [Crossref]

20. Croft PR, Lewis M, Papageorgiou AC, Thomas E, Jayson MI, et al. (2001) Risk factors for neck pain: a longitudinal study in the general population. Pain 93: 317-325. [Crossref]

21. Lau EM, Sham A, Wong KC (1996) The prevalence of and risk factors for neck pain in Hong Kong Chinese. J Publ Health Med 18: 396-399. [Crossref]

22. Makela M, Heliovaara M, Sievers K, Impivaara O; Knekt P, et al. (1991) Prevalence, determinants, and consequences of chronic neck pain in Finland. Am J Epidemiol 134 1356-1367. [Crossref]

23. Chiu TT, Leung AS (2006) Neck pain in Hong Kong: a telephone survey on prevalence, consequences, and risk groups. Spine 31: E540-E544. [Crossref]

24. Côté P, Cassidy JD, Carroll L (1998) The Saskatchewan health and back pain survey. The prevalence of neck pain and related disability in Saskatchewan adults. Spine 23: 1689-1698. [Crossref]

25. Fejer R, Hartvigsen J, Kyvik KO (2006) Heritability of neck pain: a population based study of 33,794 Danish twins. Rheumatology 45: 589-594. [Crossref]

26. MacGregor AJ, Andrew T, Sambrook PN, Spector TM (2004) Structural, psychological, and genetic influences on low back and neck pain: a study of adult female twins. Arthritis Rheum 51: 160-167. [Crossref]

27. Bovim G, Schrader H, Sand T (1994) Neck pain in the general population. Spine 19: 1307-1309. [Crossref]

28. Palmer KT, Syddall H, Cooper C, Coggon D (2003) Smoking and musculoskeletal disorders: findings from a British national survey. Ann Rheum Dis 62: 33-36. [Crossref]

29. Picavet HS, Schouten JS (2003) Musculoskeletal pain in the Netherlands: prevalences, consequences and risk groups, the DMC (3)-study. Pain 102: 167-178. [Crossref]

30. Ektor-Andersen J, Isacsson SO, Lindgren A, Ørbæk P (1999) The experience of pain from the shoulder-neck area related to the total body pain, self-experienced health and mental distress. The Malmø Shoulder-Neck Study group. Pain 82: 289-295. [Crossref]

31. Kim K, Uchiyama M, Liu X, Shibui K, Ohida T, et al. (2001) Somatic and psychological complaints and their correlates with insomnia in the Japanese general population. Psychosom Med 63: 441-446. [Crossref]

32. Berglund A, Alfredsson L, Cassidy JD, Jensen I, Nygren A (2000) The association between exposure to a rear-end collision and future neck or shoulder pain: a cohort study. J Clin Epidemiol 53: 1089-1094. [Crossref] 
Kristjansson E (2020) Critical considerations about the onset and epidemiology of whiplash associated disorders presented by the bone and joint decade 2000-2010 task force on neck pain

33. Côté P, Cassidy JD, Carroll L (2001) Is a lifetime history of neck injury in a traffic collision associated with prevalent neck pain, headache and depressive symptomatology? Accid Anal Prev 32: 151-159. [Crossref]

34. Bunketorp L, Stener-Victorin E, Carlsson J (2005) Neck pain and disability following motor vehicle accidents - a cohort study. Eur Spine J 14: 84-89. [Crossref]

35. Freeman MD, Croft AC, Rossignol AM, Weaver DS, Reiser M (1999) A review and methodologic critique of the literature refuting whiplash syndrome. Spine 24: 86-96. [Crossref]
36. Nordin M, Carragee E, Hogg-Johnson S, Weiner S, Hurwitz E, et al. (2008) Assessment of neck pain and its associated disorders. Results of the Bone and Joint Decade 2000-2010 Task Force on Neck Pain and Its Associated Disorders. Spine 33: S101-122. [Crossref]

37. Sterling M, Jull G, Kenardy J (2006) Physical and psychological factors maintain longterm predictive capacity post whiplash injury. Pain 122: 102-108. [Crossref]

38. Sterling M, Hendrikz J, Kenardy J (2010) Compensation claim lodgment and health outcome developmental trajectories following whiplash injury: a prospective study. Pain 150: 22-28. [Crossref]

Copyright: (C2020 Kristjansson E. This is an open-access article distributed under the terms of the Creative Commons Attribution License, which permits unrestricted use, distribution, and reproduction in any medium, provided the original author and source are credited. 